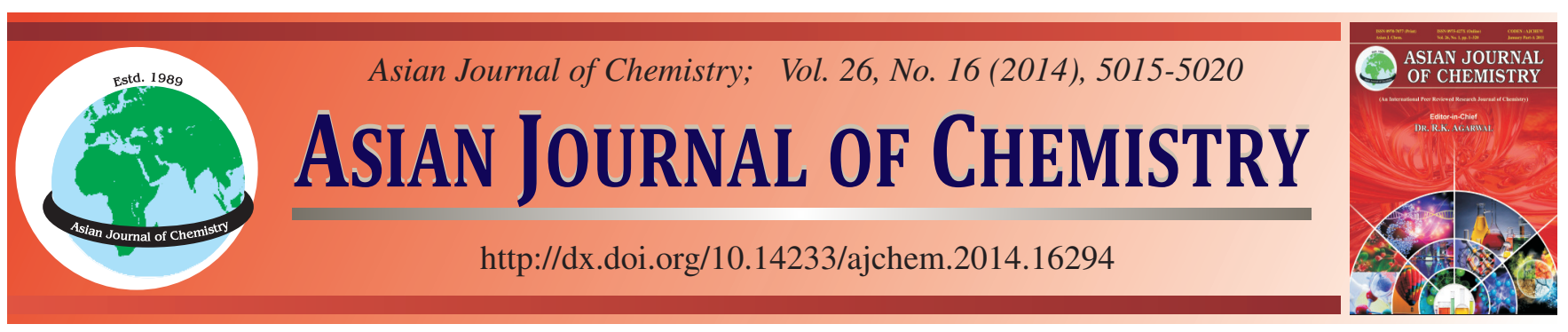

\title{
Synthesis and Quality Control of 3,3'-Diamino Diphenyl Sulfone by High Performance Liquid Chromatography
}

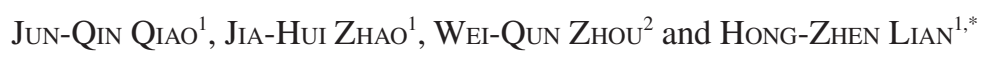

${ }^{1}$ Center of Materials Analysis, School of Chemistry \& Chemical Engineering, State Key Laboratory of Analytical Chemistry for Life Science, Nanjing University, 22 Hankou Road, Nanjing 210093, P.R. China

${ }^{2}$ Nantong Radio and TV University, 169 Zhongyuan Road, Nantong 226006, P.R. China

*Corresponding author: Fax: +86 25 83325180; Tel: +86 25 83686075; E-mail: hzlian@ @ju.edu.cn

Received: 6 September 2013;

Accepted: 26 March 2014;

Published online: 28 July 2014;

AJC-15622

\begin{abstract}
An effective reversed-phase high performance liquid chromatographic method has been developed to separate industrial 3,3'-diamino diphenyl sulfone and its related substances. Separation was achieved on a reversed-phase $\mathrm{C}_{18}$ column with methanol-water (40/60, v/v) as the mobile phase and detection was operated by UV absorption at a wavelength of $250 \mathrm{~nm}$. One unknown impurity, 3,4'-diamino diphenyl sulfone, was identified by the combination of liquid chromatography-mass spectrometry and relationship between RP-HPLC retention and hydrophobicity of the compounds studied. Partial related impurities, 4,4'-diamino diphenyl sulfone, 3,4'-diamino diphenyl sulfone and 3-amino-3'-nitro diphenyl sulfone were determined under the proposed chromatographic condition with relative standard deviations lower than $4.4 \%$. On the basis of good separation and reliable determination of related substances in 3,3'-diamino diphenyl sulfone, the chromatographic fingerprint of industrial 3,3'-diamino diphenyl sulfone was established, by which quality assessment of 3,3'-diamino diphenyl sulfone could be facilitated for industrial use.
\end{abstract}

Keywords: Reverse-phase high performance liquid chromatography, 3,3'-Diamino diphenyl sulfone, Chromatographic fingerprint.

\section{INTRODUCTION}

3,3'-Diamino diphenyl sulfone is mainly used as a curing agent of epoxy resins and the cured resins exhibit good mechanical and insulating properties and antimicrobial resistance. It is also the intermediate of heat-resistant resins, polysulfones and other polymers ${ }^{1-4}$. For instance, the addition of 3,3'-diamino diphenyl sulfone in polycondensation of 4,4'-diamino diphenyl sulfone and terephthaloyl chloride (TPC) endues the poly(amide-sulfone), 4,4'-diamino diphenyl sulfone/terephthaloyl chloride/3,3'-diamino diphenyl sulfone (4,4'-DADPS/TPC/ 3,3'-DADPS), with higher solubility than 4,4'-diamino diphenyl sulfone/terephthaloyl chloride condensation polymer due to lower molecular symmetry of 3,3'-diamino diphenyl sulfone than 4,4'-diamino diphenyl sulfone ${ }^{4}$. Besides, 3,3'diamino diphenyl sulfone is applied widely in the preparation of pesticides, medicines and dyes. The dyes using 3,3'-diamino diphenyl sulfone as intermediate present gorgeous color and excellent performance. Because the toxicity of 3,3'-diamino diphenyl sulfone is very low, it can substitute carcinogenic intermediates such as 3,3'-dimethoxybenzidine and consequently, it has broad application prospect ${ }^{5}$. Recently, 3,3'-diamino diphenyl sulfone dissolved in ethanol was mixed directly with monophosphoric acid to prepare a new organic-inorganic hybrid crystal material, $\left[\mathrm{C}_{48} \mathrm{H}_{51} \mathrm{~N}_{8} \mathrm{O}_{8} \mathrm{~S}_{4}\right]\left(\mathrm{HPO}_{4}\right) \mathrm{H}_{2} \mathrm{PO}_{4}$, which has a noncentrosymmetric structure and can be a good candidate for nonlinear optic applications ${ }^{6}$.

The easiest method of introducing an amino group in 3-position appeared to be by nitration of the proper sulfone, a meta-directing group, followed by reduction ${ }^{7}$. In industry, 3,3'diamino diphenyl sulfone is synthesized via reduction of 3,3'dinitro diphenyl sulfone generated from the nitration reaction of diphenyl sulfone (DPS) as shown in Fig. 1. The reduction reaction can be performed by using iron powder ${ }^{3,8}$, sodium sulfide $^{3,7}$, ammonium sulfide ${ }^{7}$, Adams' catalyst ${ }^{7}$, hydrazine hydrate $^{9}$ and zinc-hydrochloric acid ${ }^{1}$ as reducing agents, or through hydrogenation ${ }^{2,3}$ and electrolyzation ${ }^{1}$. Among them, the reduction by hydrazine hydrate only produces nitrogen and water as side-products, rather than side-products harmful to the environment and the reaction performed under atmospheric pressure not only has high conversion rate but also needs simple post-processing. Therefore, hydrazine hydrate has a great advantage in the reduction of nitro ${ }^{10}$.

From the synthetic route, it can be concluded that while $3,3^{\prime}$-dinitro diphenyl sulfone is generated from diphenyl sulfone, its isomers such as 2,2'-, 2,3'-, 2,4'-, 3,4'- and 4,4'- 


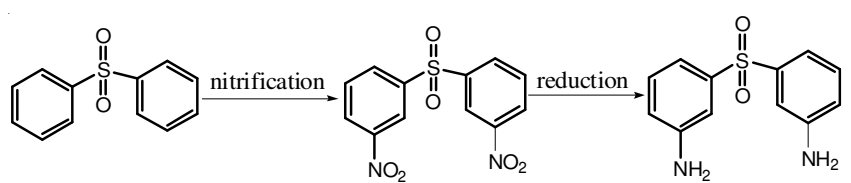

Fig. 1. Synthetic method of 3,3'-diamino diphenyl sulfone

dinitro diphenyl sulfone are inevitably produced since nitro group has different selectivity in different positions. These isomers would be converted into 2,2'-, 2,3'-, 2,4'-, 3,4'- and 4,4'-diamino diphenyl sulfone, respectively, via the subsequent reduction reaction ${ }^{2}$. In addition, 3-amino-3'-nitro diphenyl sulfone (3,3'-ANDPS), as well as 2,2'-, 2,3'-, 2,4'-, 3,4'- and $4,4^{\prime}$-ANDPS may also exist in the product because of the partial reduction of 3,3'-dinitro diphenyl sulfone, as well as 2,2'-, 2,3', 2,4'-, 3,4'- and 4,4'-dinitro diphenyl sulfone, respectively. From the viewpoint of chromatographic fingerprint of fine chemicals $^{11,12}$, the relative substances mentioned above constitute the basic "impurity group" of 3,3'-diamino diphenyl sulfone for industrial use. The reason why it is called "basic" is because the structure of some impurities is not exactly clear. However, this ambiguity does not embarrass the establishment of chromatographic fingerprint ${ }^{13,14}$. All of the above relative substances would influence the content and the quality of 3,3'-diamino diphenyl sulfone product, so they must be strictly controlled.

However, the studies of 3,3'-diamino diphenyl sulfone mainly focus on its preparation ${ }^{2,7}$. At present, only non-aqueous titration method was reported for the assay of 3,3'-diamino diphenyl sulfone ${ }^{15}$, which aimed at the determination of main content. There has not been any report about the analysis of related impurities in industrial 3,3'-diamino diphenyl sulfone up to date. In this paper, the separation of relative substances in 3,3'-diamino diphenyl sulfone for industrial use was realized by means of HPLC-UV detection. LC-MS/MS was employed to further identify the related impurities. In addition, chromatographic fingerprint of industrial 3,3'-diamino diphenyl sulfone was established on the basis of the analysis of a series of industrial 3,3'-diamino diphenyl sulfone through the same production method.

\section{EXPERIMENTAL}

Instrumentation for HPLC analysis was an Agilent 1200 series consisted of a vacuum degasser, a quaternary pump, an auto-sampler, a thermostatted column compartment, a diode array detector (DAD) and a chemstation (Agilent, Santa Clara, USA).

The LC-MS system consisted of an Agilent 1290 infinity LC system (Agilent, Waldbronn, German) coupled to a 6460 triple quadrupole mass spectrometer (Agilent, Santa Clara, USA). Data acquisition was carried out by Agilent Masshunter software.

Methanol and acetonitrile were both HPLC grade (Honeywell, Ulsan, Korea). Purified water (Wahaha Group Co., Ltd. Hangzhou, China) was used throughout the experiment. Reference substances (RSs) of 3,3'-diamino diphenyl sulfone and 4,4'-diamino diphenyl sulfone were kindly provided by Yangzhong Synthetic Chemical Plant (Zhenjiang, China). RS of 3-amino-3'-nitro diphenyl sulfone was supplied by Nanjing University of Technology. Industrial products of 3,3'-diamino diphenyl sulfone were also from Yangzhong Synthetic Chemical Plant.

HPLC condition: HPLC separation was achieved on an Ultimate XB-C18 column $(150 \times 4.6$ mm I.D., $5 \mu \mathrm{m}$; Welch Materials, Inc., Shanghai, China). The column temperature was maintained at $30^{\circ} \mathrm{C}$. The mobile phase consisted of methanol and water $(40 / 60, \mathrm{v} / \mathrm{v})$ at a flow rate of $1 \mathrm{~mL} / \mathrm{min}$. The injection volume was $10 \mu \mathrm{L}$. The effluent was monitored by DAD detector set at $250 \mathrm{~nm}$.

LC-MS condition: LC-MS separation was achieved on a ZORBAX Eclipse XDB-C ${ }_{18}$ column $(2.1 \times 150$ mm I.D., 3.5 $\mu \mathrm{m}$, Agilent Technology, USA) at a mobile phase flow rate of $0.2 \mathrm{~mL} / \mathrm{min}$. Injection volume was $2 \mu \mathrm{L}$. Other conditions were the same as those in HPLC. Electrospray ionization (ESI)-MS survey scan was conducted at mass range from 70 to 700 in positive ion mode. Parameters: gas temperature, $350{ }^{\circ} \mathrm{C}$; gas flow, $8 \mathrm{~L} / \mathrm{min}$; nebulizer pressure, $45 \mathrm{psi}$; sheath gas temperature, $250{ }^{\circ} \mathrm{C}$; sheath gas flow, $10 \mathrm{~L} / \mathrm{min}$; capillary voltage, $4000 \mathrm{~V}$; The induced collision dissociation energy of MS/MS was $15 \mathrm{~V}$.

Standard solutions: Stock solutions were prepared by

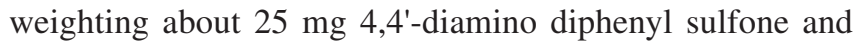
$25 \mathrm{mg}$ 3-amino-3'-nitro diphenyl sulfone RSs to two $25 \mathrm{~mL}$ volumetric flasks, respectively, adding $10 \mathrm{~mL}$ methanol to dissolve and making up to the mark with water after 1 min sonication. Mixed standard solutions at concentration of $1 \times 10^{-5}$ to $0.1 \mathrm{~g} \mathrm{~L}^{-1}$ each component were prepared by serial dilution of the above stock solutions with mixture of methanolwater $(40 / 60, \mathrm{v} / \mathrm{v})$.

Sample solutions: For HPLC analysis, about $25 \mathrm{mg}$ industrial 3,3'-diamino diphenyl sulfone was weighed to a $25 \mathrm{~mL}$ flask, dissolved by $10 \mathrm{~mL}$ methanol and made up to the mark with water after $1 \mathrm{~min}$ sonication. For LC-MS analysis, 3,3'-diamino diphenyl sulfone sample solution was diluted 10 times.

\section{RESULTS AND DISCUSSION}

\section{Selection of mobile phase}

Organic modifier: An optional 3,3'-diamino diphenyl sulfone sample solution spiked with 4,4'-diamino diphenyl sulfone and 3-amino-3'-nitro diphenyl sulfone standard solutions was analyzed using isocratic elution with acetonitrilewater and methanol-water as mobile phases, respectively. Typical separation performance is compared in Fig. 2. Almost all the components in the sample solution have good separation when acetonitrile-water $(35 / 65, \mathrm{v} / \mathrm{v})$ was used as mobile phase, but unknown peaks 4 in 3,3'-diamino diphenyl sulfone sample and $\mathrm{I}_{1}$ from 3-amino-3'-nitro diphenyl sulfone RS were overlapped. While using methanol-water (40/60, v/v) as mobile phase, a baseline separation of peaks 4 and $\mathrm{I}_{1}$ was realized in shorter running time. In addition, considering the toxicity and price of acetonitrile, methanol was finally selected as the organic modifier.

Methanol proportion: An optional 3,3'-diamino diphenyl sulfone sample solution spiked with 4,4'-diamino diphenyl sulfone and 3-amino-3'-nitro diphenyl sulfone RSs was analyzed 


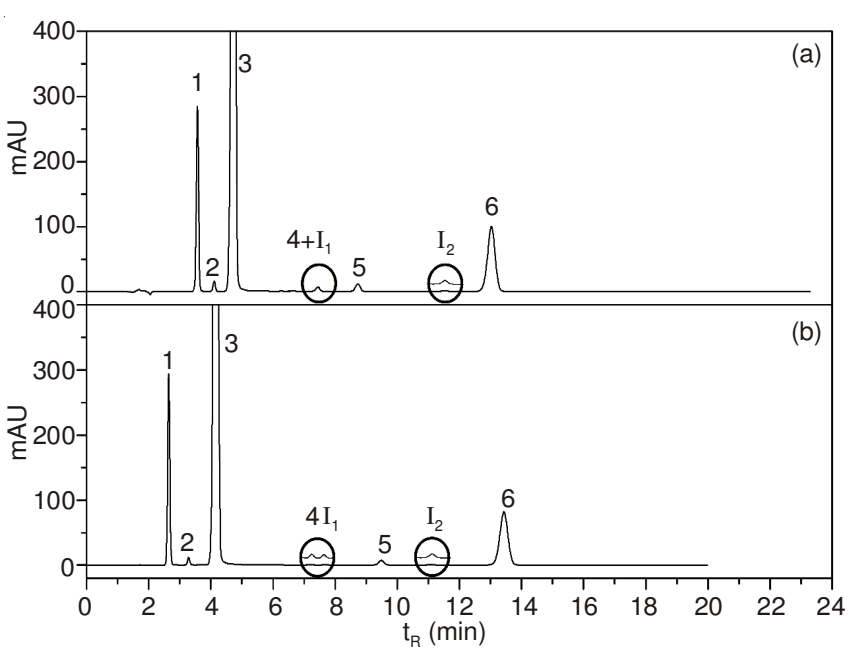

Fig. 2. Chromatograms of 3,3'-diamino diphenyl sulfone sample solution spiked with 4,4'-diamino diphenyl sulfone and 3-amino-3'-nitro diphenyl sulfone RSs using different organic modifier. Column: Ultimate XB-C18, $150 \mathrm{~mm} \times 4.6 \mathrm{~mm}$ i.d., $5 \mu \mathrm{m}$; Column temperature: $30{ }^{\circ} \mathrm{C}$; Flow rate: $1 \mathrm{~mL} / \mathrm{min}$; Injection volume: 10 $\mu \mathrm{L}$; Wavelength for UV detection: $250 \mathrm{~nm}$; Mobile phase: (a) Acetonitrile-water (35/65, v/v); (b) Methanol-water (40/60, v/v). Peaks: 1. 4,4'-diamino diphenyl sulfone; 2,4,5. Unknown impurities in the sample; 3. 3,3'-diamino diphenyl sulfone; 6. 3-amino-3'-nitro diphenyl sulfone; $\mathrm{I}_{1}, \mathrm{I}_{2}$. Unknown impurities introduced from 3amino-3'-nitro diphenyl sulfone RS

using different methanol proportion in methanol-water (a: 50/ 50, b: 40/60, c: 35/65, v/v) as mobile phase, respectively. Separation performance is shown in Fig. 3. When using mobile phase a (50\% methanol), peaks 1,2 and 3 could not be effectively separated and peaks 4 and $\mathrm{I}_{1}$ were overlapped. Using mobile phase b, peaks 1, 2 and 3 were baseline separated and peaks 4 and $\mathrm{I}_{1}$ were clearly distinguished as well (The magnified chromatogram was the same as Fig. 2b). While using $35 \%$ methanol as mobile phase, despite a good separation, it took too long running time. The retention time of analytes decreased significantly when methanol proportion increased from 35 to $50 \%$ with a gradually reduced resolution. It can be observed that methanol proportion has significant impact on analysis

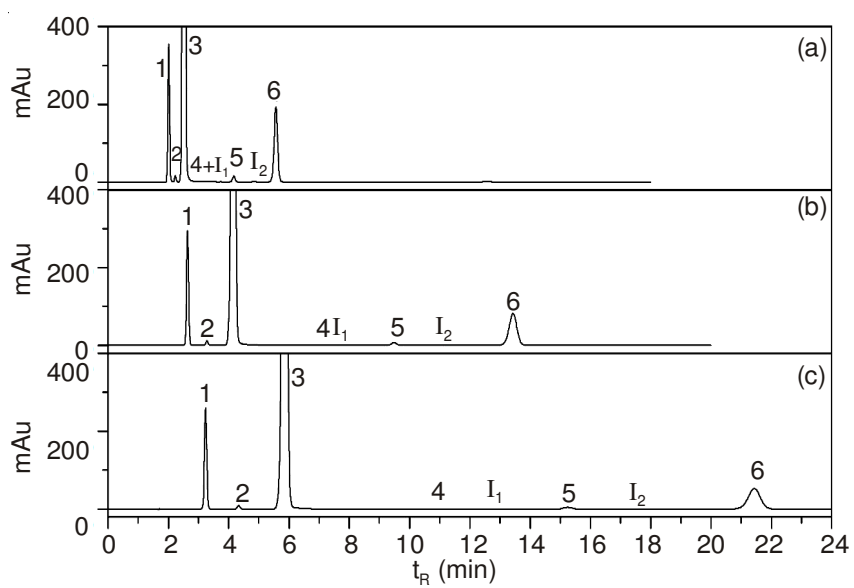

Fig. 3. Chromatograms of 3,3'-diamino diphenyl sulfone sample spiked with 4,4'-diamino diphenyl sulfone and 3,3-ANDPS RSs under different proportion of methanol. Mobile phase: (a) Methanol-water (50/50, v/v); (b) Methanol-water (40/60, v/v); (c) Methanol-water $(35 / 65, v / v)$. Other HPLC conditions were the same as in Fig. 2. The peak numbers were the same as in Fig. 2 time and separation effect in this RP-HPLC separation mode. Taking separation effect and analysis time into consideration, $40 \%$ methanol proportion in mobile phase was selected in the following experiment.

Selection of UV detection wavelength: The UV-visible spectra of 4,4'-diamino diphenyl sulfone, 3,3'-diamino diphenyl sulfone and 3-amino-3'-nitro diphenyl sulfone, as well as unknown impurities were recorded by on-line DAD scan (Fig. 4). The characteristic absorption of 3,3'-diamino diphenyl sulfone was at 228 and $308 \mathrm{~nm}$, that of 4,4'-diamino diphenyl sulfone at 258.7 and $292.9 \mathrm{~nm}$, that of 3-amino-3'-nitro diphenyl sulfone was at 227.6 and $320.0 \mathrm{~nm}$ and that of unknown impurity 2 at 213.8 and $283.0 \mathrm{~nm}$. The UV-visible absorptions of rest impurities were too small to acquire correctly. It is found that all the compounds of interest have relatively high signal-to-noise ratio $(\mathrm{S} / \mathrm{N})$ at $250 \mathrm{~nm}$, therefore, comprehensively considering the high sensitivity of each analytes $250 \mathrm{~nm}$ was selected as the detection wavelength.

Identification of unknown impurities: In Fig. 2b, peaks 1 and 6 were assigned to be 4,4'-diamino diphenyl sulfone and 3-amino-3'-nitro diphenyl sulfone, respectively by comparing the retention times and UV spectra with those of reference substances. Since the UV-visible spectrum of unknown impurity 2 was like that of 4,4'-diamino diphenyl sulfone in feature, impurity 2 was temporarily considered as an isomer of 4,4'-diamino diphenyl sulfone. Moreover, LC-MS and LCMS/MS method were used to deduce the structure of this unknown impurity.

With LC-MS full scan mode, the mass spectrum of unknown impurity 2 revealed the same with that of 3,3'- and 4,4'-diamino diphenyl sulfone (Fig. 5). The significant quasimolecular ion peaks of $m / z=249.5,271.3,287.0,519.1$ corresponded to $[\mathrm{M}+\mathrm{H}]^{+},[\mathrm{M}+\mathrm{Na}]^{+},[\mathrm{M}+\mathrm{K}]^{+}$and $[2 \mathrm{M}+$ $\mathrm{Na}]^{+}$, respectively. Therefore, it can be concluded that the molecular weight of the unknown impurity is equal to that of 3,3'- and 4,4'-diamino diphenyl sulfone, namely, 248.

In order to confirm the structure, the quasi-molecular ion peak $m / z=249.1$ of unknown impurity 2 was analyzed using LC-MS/MS method. The mass spectrum is shown in Fig. 6. The product ion peaks $m / z=92,108.3$ and 156 of unknown impurity 2 are the same with those of 3,3'- and 4,4'-diamino diphenyl sulfone. These three product ions correspond to

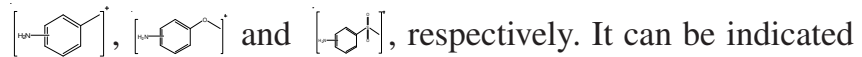
that the structure of unknown impurity 2 is identical to that of 3,3'- and 4,4'-diamino diphenyl sulfone and they are certainly isomers. As it is known from the synthetic route (Fig. 1) of 3,3'-diamino diphenyl sulfone, 2,2'-, 2,3'-, 2,4'-, 3,4'- and 4,4'diamino diphenyl sulfone are the potential impurities ${ }^{2}$. The information from the commercial website of polysciences mentions that the content of 3,4'-isomer is one of the specifications of 3,3'-diamino diphenyl sulfone product ${ }^{16}$. In addition, the octonal-water partition coefficients $(\log \mathrm{P})$ of 4,4'-, 3,4'-, 3,3'-, 2,4'-, 2,3'- and 2,2'- DADPS increases in turn (Table-1). The unknown impurity eluted at retention time $\left(t_{R}\right)$ of 3.28 min was between 4,4'- and 3,3'-diamino diphenyl sulfone in RP-HPLC, reflecting its hydrophobicity is between 4,4'- and 3,3'-diamino diphenyl sulfone. Therefore, we can reasonably deduce that unknown impurity 2 is likely $3,4^{\prime}$-diamino diphenyl sulfone. 

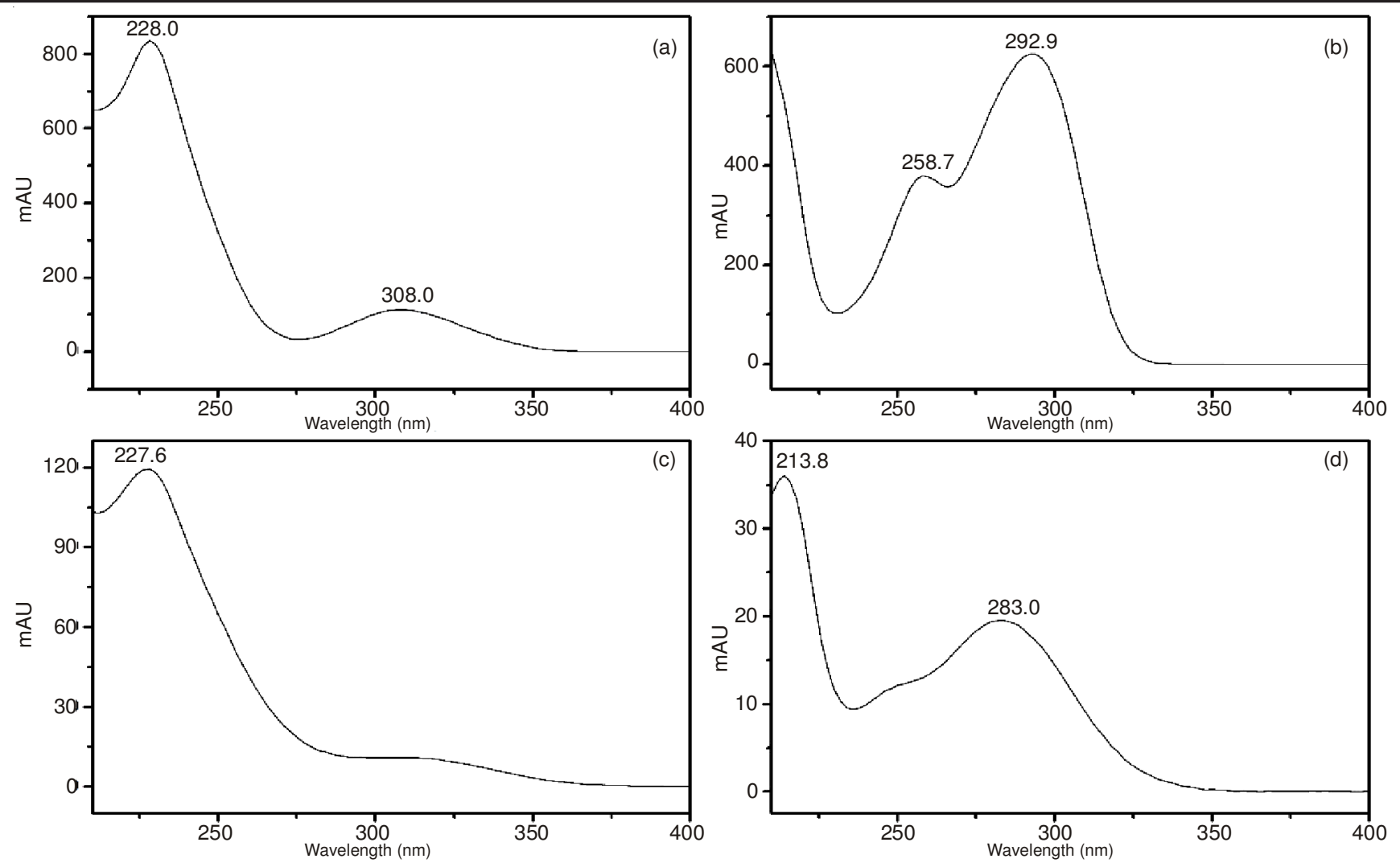

Fig. 4. On-line UV-visible spectra of 3,3'-diamino diphenyl sulfone and related impurities. (a) 3,3'-diamino diphenyl sulfone; (b) 4,4'-diamino diphenyl sulfone; (c) 3-amino-3'-nitro diphenyl sulfone; (d) Unknown impurity 2; Other HPLC conditions were the same as Fig. 2b

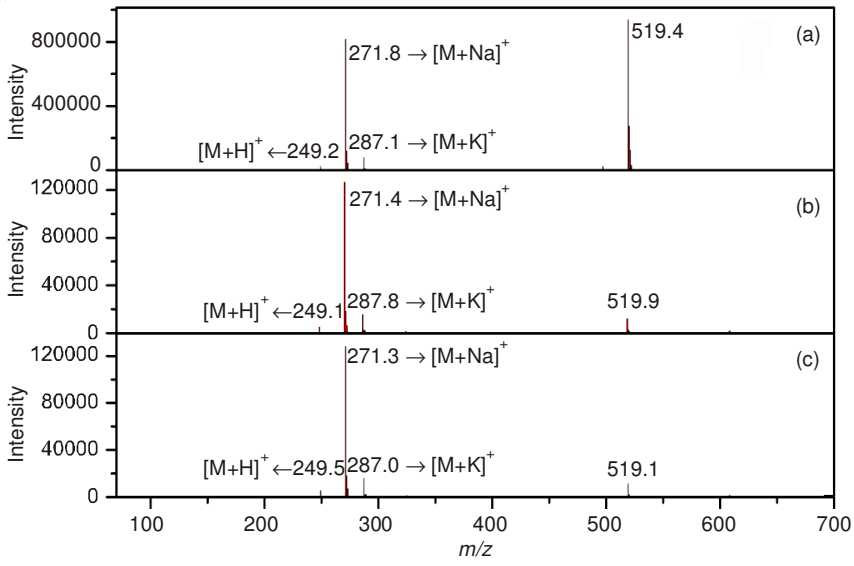

Fig. 5. Full Scan mass spectra of 3,3'-diamino diphenyl sulfone (a), 4,4'diamino diphenyl sulfone (b) and unknown impurity 2 (c) by LCMS. Column: ZORBAX Eclipse XDB-C $18,2.1 \mathrm{~mm} \times 150 \mathrm{~mm}$ i.d. $3.5 \mu \mathrm{m}$; Column temperature: $30^{\circ} \mathrm{C}$; Mobile phase: methanol-water solution (40/60,v/v); Flow rate: $0.2 \mathrm{~mL} / \mathrm{min}$; Injection volume: 2 $\mu \mathrm{L}$; Wavelength for UV detection: $250 \mathrm{~nm}$; ESI(+)-MS scan range: 70-700; MS Parameters: gas temperature, $350{ }^{\circ} \mathrm{C}$; gas flow, $8 \mathrm{~L} /$ $\mathrm{min}$; nebulizer, $45 \mathrm{psi}$; sheath gas temperature, $250{ }^{\circ} \mathrm{C}$; sheath gas flow, $10 \mathrm{~L} / \mathrm{min}$; capillary voltage, $4000 \mathrm{~V}$ and $3500 \mathrm{~V}$ in positive ion mode

Neither distinct UV nor MS spectra of unknown impurities 4 and 5 in 3,3'-diamino diphenyl sulfone samples and $I_{1}$ and $I_{2}$ from 3-amino-3'-nitro diphenyl sulfone RS were not obtained probably because their contents were very low in respect of the normalized peak area percentage (A \%) by HPLC-UV detection, respectively. Therefore, these impurities were not further identified.

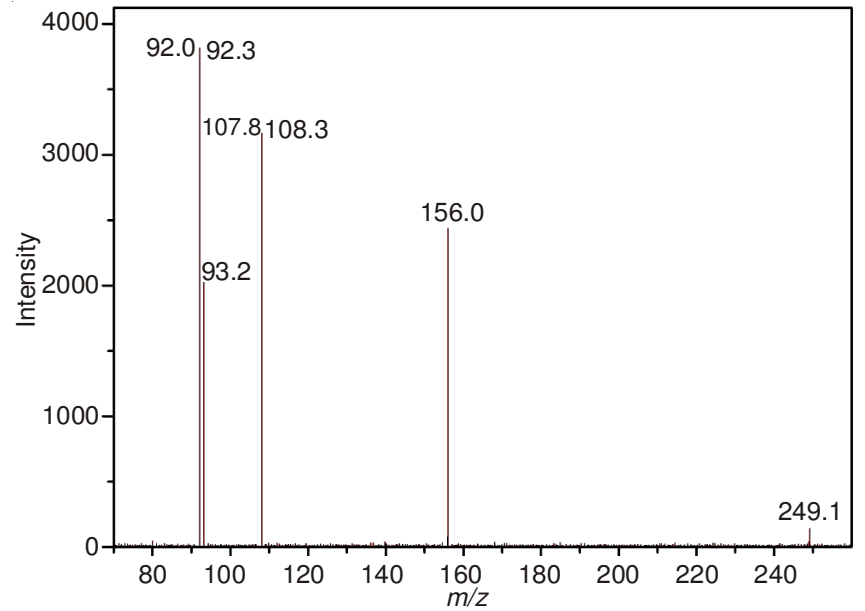

Fig. 6. Daughter scan spectrum of the unknown impurity by LC-MS/MS. Induced collision dissociation energy of MS/MS: $15 \mathrm{~V}$. Other conditions are the same as in Fig. 5

TABLE-1

$\log$ P OF THE ISOMERS OF 3,3'-DIAMINO DIPHENYL SULFONE

\begin{tabular}{ccc}
\hline Component & CAS number & LogP* \\
\hline 4,4'-DADPS & $80-08-0$ & $0.991 \pm 0.340$ \\
3,4'- DADPS & $34262-32-3$ & $1.030 \pm 0.345$ \\
3,3'- DADPS & $599-61-1$ & $1.069 \pm 0.349$ \\
2,4'- DADPS & $27147-69-9$ & $1.435 \pm 0.448$ \\
2,3'- DADPS & $34262-29-8$ & $1.474 \pm 0.451$ \\
$2,2^{\prime}$ - DADPS & $53347-49-2$ & $1.879 \pm 0.534$ \\
\hline
\end{tabular}

*Calculated using Advanced Chemistry Development (ACD/Labs)

Software V11.02 (copyright: 1994-2013 ACD/Labs) 
Calibration curve and detection limit: Linearity of calibration curves of 4,4'-diamino diphenyl sulfone and 3amino-3'-nitro diphenyl sulfone were obtained from the regression of peak area $(\mathrm{A}, \mathrm{mAU} * \mathrm{sec})$ versus concentration $\left(\mathrm{C}, \mu \mathrm{g} \mathrm{mL}^{-1}\right)$ of respective RSs. The limits of detection (LOD) and limit of quantitation (LOQ) were defined as the concentration where the peak height was three and ten times the background, respectively (Table-2). Mixed standard solution of $10 \mu \mathrm{g} \mathrm{mL}^{-1}$ was injected five times repeatedly. The relative standard deviations (RSDs) of peak area and retention time of 4,4'-diamino diphenyl sulfone and 3-amino-3'-nitro diphenyl sulfone were $0.2 \%$ and $0.3 \%$, and $0.1 \%$ and $0.3 \%$, respectively.

\begin{tabular}{ccccc}
\multicolumn{5}{c}{ TABLE-2 } \\
STANDARD CURVES AND DETECTION LIMITS \\
\hline Component & $\begin{array}{c}\text { Linear } \\
\text { range } \\
\left(\mu \mathrm{g} \mathrm{mL} \mathrm{mL}^{-1}\right)\end{array}$ & Linear equation & $\mathrm{R}^{2}$ & $\begin{array}{c}\text { LOD } \\
\left(\mu \mathrm{g} \mathrm{mL}^{-1}\right)\end{array}$ \\
\hline 4,4'-DADPS & $0.05-100$ & $\mathrm{~A}=28451.8 \mathrm{C}+5.91628$ & 0.9999 & 0.02 \\
3,3'-ANDPS & $0.3-100$ & $\mathrm{~A}=31550.1 \mathrm{C}-8.48583$ & 0.9991 & 0.07 \\
\hline
\end{tabular}

Analysis of relative impurities in industrial 3,3'-diamino diphenyl sulfone products: The 3,3'-diamino diphenyl sulfone sample solutions were prepared in quintuplicates separately to carry on intra-day precision measurements. The HPLC chromatogram of a typical industrial 3,3'-diamino diphenyl sulfone is shown in Fig. 7. The inter-day determination was accomplished by preparing and analyzing 3,3'-diamino diphenyl sulfone sample solutions $(n=5)$ in five consecutive days. The analytical results with intra- and inter-day relative standard deviations are presented in Table-3. 4,4'-diamino diphenyl sulfone and 3-amino-3'-nitro diphenyl sulfone were quantified with external standard method, while 3,4'-diamino diphenyl sulfone with self-control method (The peak area of $3,4^{\prime}$-diamino diphenyl sulfone in sample solution was compared with that of 3,3'-diamino diphenyl sulfone in the sample solution diluted 100 times). The method shows a good accuracy with all intra- and inter-day relative standard deviations lower than $4.4 \%$.

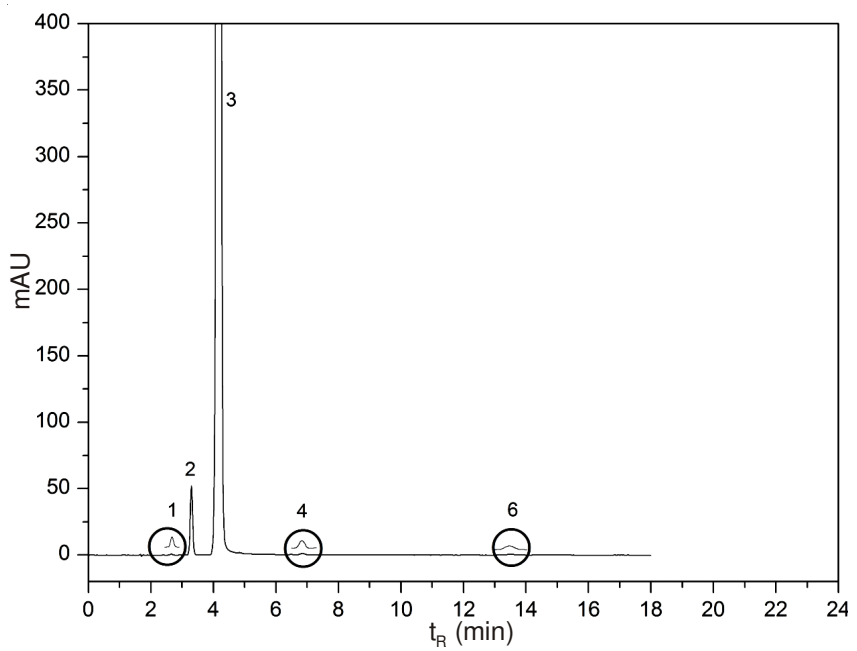

Fig. 7. Chromatographic fingerprint of industrial 3,3'-diamino diphenyl sulfone. HPLC conditions were the same as in Fig. 2b. The peak numbers were the same as in Fig. 2b

\begin{tabular}{|c|c|c|c|c|}
\hline \multicolumn{5}{|c|}{$\begin{array}{l}\text { TABLE-3 } \\
\text { DETERMINATION OF RELATIVE IMPURITIES IN } \\
\text { INDUSTRIAL 3,3'-DIAMINO DIPHENYL SULFONE }\end{array}$} \\
\hline \multirow{2}{*}{ Component } & \multicolumn{2}{|c|}{ Intra-day } & \multicolumn{2}{|c|}{ Inter-day } \\
\hline & Content $(\%)$ & $\operatorname{RSD}(\%)$ & Content (\%) & RSD (\%) \\
\hline 4,4'-DADPS & 0.02 & 4.4 & 0.01 & 2.9 \\
\hline 3, $3^{\prime}$-ANDPS & 0.03 & 2.9 & 0.03 & 4.3 \\
\hline 3,4'-DADPS* & 0.89 & 1.3 & 0.92 & 1.3 \\
\hline Unknown impurity $4 *$ & 0.03 & 1.1 & 0.03 & 3.3 \\
\hline
\end{tabular}

Recoveries were obtained by spiking a known amount of 4,4'-diamino diphenyl sulfone and 3-amino-3'-nitro diphenyl sulfone RSs to a 3,3'-diamino diphenyl sulfone sample solution. Three levels of standards were added and three replicates at each level were performed for the test. The results are shown in Table-4. The recovery ranges of 4,4'-diamino diphenyl sulfone and 3-amino-3'-nitro diphenyl sulfone were 94.71-98.89 and 96.46-99.16\%, respectively, showing a good accuracy.

\begin{tabular}{lccccc}
\multicolumn{7}{c}{ TABLE-4 } \\
RESULTS OF RECOVERY TEST \\
Component & $\begin{array}{c}\text { Back } \\
\text { ground } \\
\left(\mu \mathrm{g} \mathrm{mL}^{-1}\right)\end{array}$ & $\begin{array}{c}\text { Added } \\
\left(\mu \mathrm{g} \mathrm{mL}^{-1}\right)\end{array}$ & $\begin{array}{c}\text { Detected } \\
\left(\mu \mathrm{g} \mathrm{mL}^{-1}\right)\end{array}$ & $\begin{array}{c}\text { Recovery } \\
(\%)\end{array}$ & $\begin{array}{c}\text { RSD } \\
(\%, \mathrm{n}=3)\end{array}$ \\
\hline 4,4'-DADPS & 0.137 & 0.075 & 0.208 & 94.71 & 0.3 \\
& 0.143 & 0.150 & 0.290 & 97.99 & 1.6 \\
& 0.138 & 0.300 & 0.435 & 98.89 & 1.6 \\
\hline 3,3'-ANDPS & 0.281 & 0.148 & 0.442 & 96.46 & 0.2 \\
& 0.275 & 0.296 & 0.620 & 98.40 & 0.1 \\
& 0.273 & 0.593 & 0.930 & 99.16 & 0.1 \\
\hline
\end{tabular}

Establishment of chromatographic fingerprint of industrial 3,3'-diamino diphenyl sulfone: Eight batch of industrial 3,3'-diamino diphenyl sulfone were analyzed under the proposed chromatographic condition and the related impurities determined are shown in Table-5. The acceptable chromatographic fingerprint of 3,3'-diamino diphenyl sulfone industrial product is shown in Fig. 7. Despite tiny difference, for the products from one workshop, the chromatograms of 3,3'-diamino diphenyl sulfone samples are fairly similar. In general, the common peaks of 4,4'-diamino diphenyl sulfone, 3,4'-diamino diphenyl sulfone and 3-amino-3'-nitro diphenyl sulfone fall on the "impurity group" of industrial 3,3'-diamino diphenyl sulfone. If the chromatogram of some 3,3'-diamino diphenyl sulfone product is similar with the fingerprint, we can rapidly estimate that it is primarily eligible. Otherwise, it is unqualified ${ }^{12}$. Consequently, the proposed fingerprint is of significant importance for supplying an easy way for quality assessment of 3,3'-diamino diphenyl sulfone and related industrial products.

\section{Conclusion}

A reliable RP-HPLC method with UV detection was developed for the separation and determination of 3,3'-diamino diphenyl sulfone for industrial use and its relative substances. On this basis, the chromatographic fingerprint of industrial 3,3'-diamino diphenyl sulfone was established, which can supply a facile way for quality control of 3,3'-diamino diphenyl sulfone, as well as its related products including 3-amino-3'nitro diphenyl sulfone, 3,4'-diamino diphenyl sulfone, 4,4'diamino diphenyl sulfone and the like. 


\begin{tabular}{|c|c|c|c|c|}
\hline & $\begin{array}{r}\text { DETERM } \\
\text { SUBST } \\
\text { 3,3'-DIAMIN } \\
\end{array}$ & $\begin{array}{l}\text { TABLE } \\
\text { NATION OF P } \\
\text { ANCES IN EIG } \\
\text { O DIPHENYL }\end{array}$ & $\begin{array}{l}5 \\
\text { RTIAL RELATI } \\
\text { IT BATCHES OF } \\
\text { ULFONE PROD }\end{array}$ & $\begin{array}{l}\text { JE } \\
\text { JCTS }\end{array}$ \\
\hline Batch & 4,4'-DADPS & 3,4'-DADPS* & 3,3'-ANDPS** & $\begin{array}{l}\text { Unknown } \\
\text { impurity } 4 *\end{array}$ \\
\hline & & & b) & \\
\hline 1 & 0.006 & 1.015 & 0.020 & 0.026 \\
\hline 2 & 0.007 & 1.026 & 0.028 & 0.026 \\
\hline 3 & 0.017 & 0.891 & 0.031 & 0.025 \\
\hline 4 & 0.011 & 0.908 & 0.015 & 0.032 \\
\hline 5 & 0.007 & 1.101 & 0.020 & 0.023 \\
\hline 6 & 0.075 & 0.950 & 0.019 & 0.019 \\
\hline 7 & 0.052 & 0.971 & 0.016 & 0.024 \\
\hline 8 & 0.007 & 1.138 & 0.019 & 0.030 \\
\hline
\end{tabular}

\section{ACKNOWLEDGEMENTS}

This work was supported by National Basic Research Program of China (973 program, 2009CB421601, 2011CB911003), National Natural Science Foundation of China $(21275069,90913012,21121091)$ and Starting Fund for Young Teachers and Analysis \& Test Fund of Center of Materials Analysis, Nanjing University.

\section{REFERENCES}

1. G. Cao, Fine Chem. Ind. Inf., 4, 40 (1988).

2. T.H. Sun, Chem. Ind. Times, 5, 32 (1999).

3. S.H. Lu, G.L. Yuan and S.D. Qi, Guangdong Chem. Ind., 39, 115 (2012).

4. Y. Qian, C.B. Huang, Q.P. Ding, C.L. Lai, S.L. Chen and F. Chen, Polym. Mater. Sci. Eng., 22, 42 (2006).

5. A. Rajagopalan, R. Rajagopal and S. Seshadri, Dyes Pigments, 9, 209 (1988).

6. A. Mahroug, M. Belhouchet and T. Mhiri, Phosphorus Sulfur Silicon Rel. Elem., 187, 1482 (2012).

7. B.R. Baker, A.F. Kadish and M.V. Querry, J. Org. Chem., 15, 400 (1950).

8. S.D. Qi, S.C. Zhu and X.Q. Zhu, CN200810054709.4 (2008).

9. F.S. Li, H.B.Zhang and W. Yao, CN200910183449.5 (2010).

10. R.W. Lv, Z.X. Zhang, Q.S. Shi, H. Zhou and D. Liang, Dyestuffs Color, 42, 43 (2005).

11. H.Z. Lian, Fine Chem. Intermed., 34, 1 (2004).

12. H.Z. Lian and Y.N. Wei, Talanta, 71, 264 (2007).

13. Y.N. Wei, C. Li and H.Z. Lian, Rock Min. Anal., 26, 81 (2007).

14. J.Q. Qiao, D. Sheng and H.Z. Lian, Talanta, 77, 1573 (2009).

15. Q. Xie, W, Yao and F.S. Li, J. Nanjing Univ. Technol. (Nat. Sci. Ed.), 31, 86 (2009).

16. http://www.polysciences.com/catalog/department/product/98/ categoryid--266/productid--1256/. 